\title{
Pediatric residents' perceptions of the impact of the 24-hour on-call system on their well-being and education and patient safety
}

\author{
A national survey
}

Fahad M. Alsohime, MD.

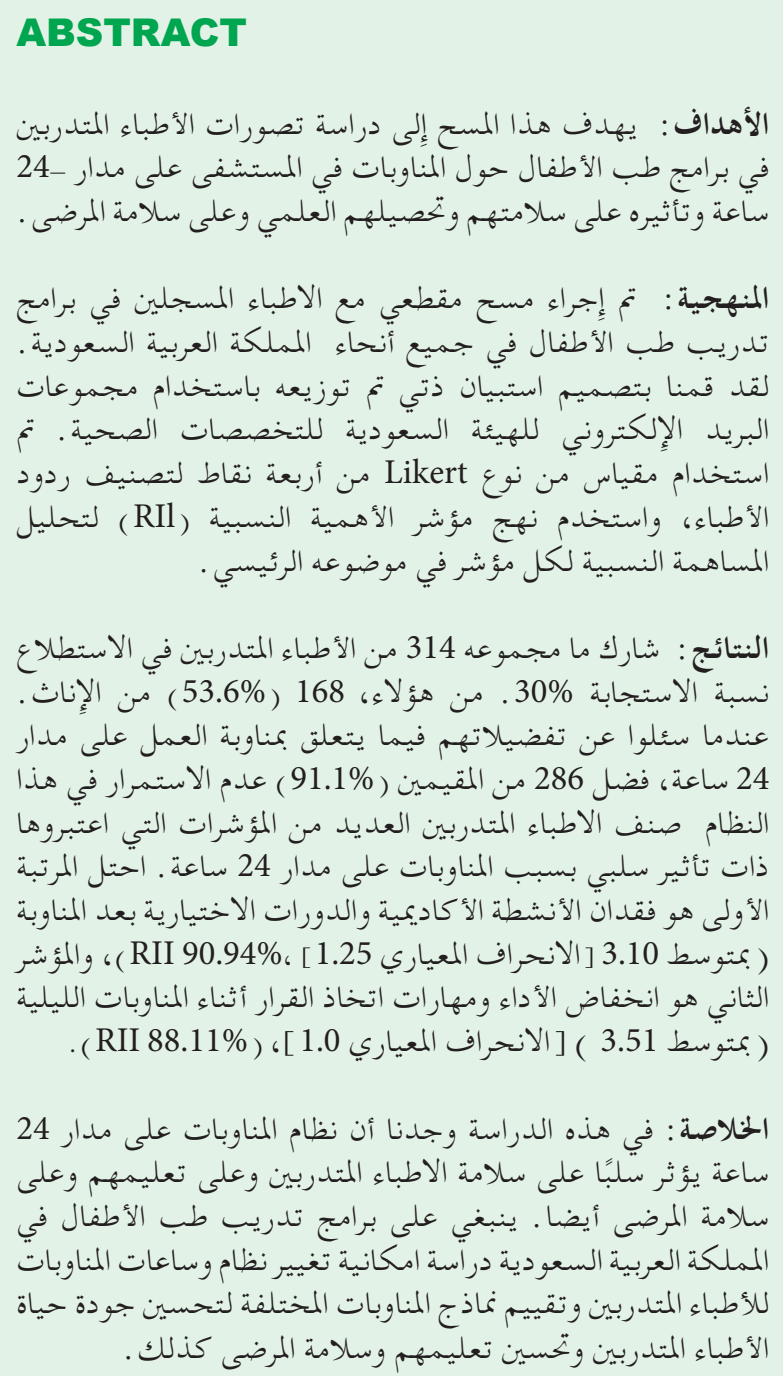

Objectives: To examine pediatric residents' perceptions of the 24-hour in-hospital shift and its impact on their well-being and education and patient safety.
Methods: A cross-sectional survey conducted with residents enrolled in pediatric residency programs across Saudi Arabia in February 2017 at the Saudi Commission For Health Specialties, Riyadh Saudi Arabia. We designed a self-administered questionnaire that was distributed using the Saudi Commission for Health Specialties E-mail groups. A 4-point Likert-type scale was used to rank the residents' responses; and the relative importance index (RII) approach was used to analyze the relative contribution of each indicator to its main theme.

Results: A total of 314 residents participated in the survey (response rate, 30\%). Of these, 168 (53.6\%) were females. When asked about their preferences regarding the 24-hour on-call system, 286 residents (91.1\%) preferred not to continue with this system. Residents ranked several indicators that they perceived as a negative impact due to the 24-hour on-call system. The first ranked indicator was missing academic activities and elective rotations post-call (mean 3.10 [standard deviation 1.25], RII 90.94\%), and the second was decreased performance and decision-making skills during night duty (mean 3.51 [standard deviation 1.0], RII 88.11\%).

Conclusion: We found that the 24-hour on-call system negatively impacts residents' well-being and education and patient care. Pediatric residency training programs in Saudi Arabia should consider resident duty hour reform and evaluate new on-call models to improve resident well-being and training, as well as patient care.

\section{Saudi Med J 2019; Vol. 40 (10): 1040-1044 doi: 10.15537/smj.2019.10.24548}

From the Pediatric Department, College of Medicine, King Saud University and from the Pediatric Intensive Care Unit, King Saud University Medical City, Riyadh, Kingdom of Saudi Arabia.

Received 2nd July 2019. Accepted 4th September 2019.

Address correspondence and reprint request to: Dr. Fahad M. Alsohime, Associate Professor, College of Medicine, King Saud University, Riyadh, Kingdom of Saudi Arabia. E-mail: falsohime@ksu.edu.sa ORCID ID: https://orcid.org/0000-0002-4979-3895 
$\mathrm{R}^{\mathrm{c}}$ esidency work hour reforms have been a subject of attention worldwide during the past decades, as several reports indicate that long duty hours and sleep deprivation are correlated with medical errors, attention dysfunction, adverse events, and resident burnout. ${ }^{1-4}$ This has led to the replacement of the traditionally longer on-call shifts ( 24 hours) to 12 to 16 hour shifts in several universities in North America. ${ }^{5-7}$ In Europe, some countries, including Denmark, Sweden, Germany, Finland, and the Netherlands, have been compliant with the European Working Time Directive, which was developed by the Council of Europe to regulate the working hours of medical staff. ${ }^{8}$ Not all European countries meet the requirements set by the Council of Europe, ${ }^{8}$ and in the United Kingdom, for example, it has been reported that up to one-quarter of residents still work beyond the 48-hour European Working Time Directive limit. ${ }^{9}$ Previously, it was demonstrated that 16-hour on-call shifts were more efficient and provided the same coverage with the same number of residents without affecting either the quantitative or qualitative aspects of residency training. ${ }^{10}$ Extremely long working hours ( $>20$ hours) can negatively affect health, and the personal effect of burnout for residents is dispiriting and includes increased rates of dysfunctional relationships, mental health issues, and self-harm behaviors. ${ }^{11}$

Structured residency training programs were established in Saudi Arabia about 40 years ago with the support and approval of the Arab Board for Medical Specialization. ${ }^{12}$ The Saudi Commission for Health Specialties was created in 1993, and this regulatory body subsequently oversaw the running of residency training programs in the kingdom, including their regulations, supervision, and examinations. ${ }^{13}$ The pediatrics residency training program was one of the first programs, and it has rapidly grown over 20 years to become a well-recognized general pediatric specialty with approximately 13 pediatric subspecialties. Since the commission's inception, the number of accredited training centers and trainees has grown consistently. ${ }^{14}$

The Saudi Commission for Health Specialties outlined some guidelines for duty hour regulations for the pediatrics program where it holds the long-standing tradition; physicians in training complete long hours of on-call work, including working shifts longer than 24 hours. The Pediatric Residency Training Program

Disclosure. Authors have no conflict of interests, and the work was not supported or funded by any drug company.
Manual states that the mean number of calls for year one and 2 residents should be limited to 7 every month whereas those for year 3 and 4 residents should be no more than 6 every month. Additionally, the average duration of the calls should be 24 hours, and residents should be off-duty by midday on the day following their call. ${ }^{15}$

This study aimed to explore pediatric residents' perceptions regarding the 24-hour in-hospital calls and the impact of these duty hour restrictions on their well-being and education and patient safety.

Methods. This cross-sectional survey is part of a larger study designed to assess pediatric residents' perceptions of their residency training competencies and skills. ${ }^{16,17}$ The inclusion criteria includes any resident registered in the Saudi Pediatric Residency Program during the academic year 2017 to 2018. We excluded the residents who were not registered in the Saudi Pediatric Residency Program.

A total of 1052 residents were registered in the program in February 2017 when the data were collected. A finite population correction was used in sample size calculation with a 95\% confidence interval and 5\% marginal error which resulted in a representative sample of 282 participants.

This study received ethical approval from the Institutional Review Board (IRB) of King Saud University. Residents were informed that participation was not mandatory and assured of the anonymity and confidentiality of their responses. Consent was obtained from the participants before their enrollment in this survey.

The survey was distributed to attendees during the Fifth Saudi Pediatric Association Conference. The survey was also circulated by E-mail via the Saudi Commission for Health Specialties E-mailing group for pediatric residents to capture data from residents who might have been absent from the conference to reach the target sample size. An online, web-based, survey tool (www.surveymonkey.com) was used to collect the responses for analysis. Two reminders were sent over 4 weeks to those who did not respond initially.

Questions were prepared based on the literature summary described above. Question wording and format were refined by a multidisciplinary team focus group. Additionally, we consulted a previous research that assessed residents' perceptions of the impact of duty hours on their performance ${ }^{18}$ before conducting a pilot test with a group of experts from the postgraduate medical education department of our institution. Questions marked as unclear were edited out of the 
questionnaire. The questionnaire was divided into the following 3 sections: The first section asked the residents to enroll in the study and provide their demographic details, including their level of training, training center, gender, and age. The second part asked questions on the residents' opinions of how the 24-hour on-call system negatively impacted the following items: i) Their overall well-being and health; ii) Their performance during the on-call time and fatigue; iii) The effect on their memory during night duty; iv) Missing the program's academic activities; v) The continuity of the patient care; vi) The patient exposure to potentially adverse events.

A 4-point Likert-type scale was used to rank residents' responses, with $1=$ no effect at all and $5=$ extreme effect. The last section asked whether the participants preferred to maintain the 24-hour on-call system or transition to 16-hour on-call shifts (night float).

Statistical analysis. The data were entered and analyzed using the Statistical Package for Social Sciences (IBM SPSS Statistics for Windows, Armonk, New York, US), version 23. Descriptive statistics were calculated for all study variables. Continuous variables are expressed as mean and standard deviation, whereas categorical and binary variables are expressed as frequency and percent.

Cronbach's $\alpha$ coefficient was used to measure the internal consistency of the survey instrument. A summative analysis and the recode features in SPSS were then used to compute means and standard deviations for each of the indicators that comprised the main perceptive concepts of the study. The relative importance index (RII), described by Holt, ${ }^{19}$ was used to determine the relative significance and ranking of the identified indicators.

Results. A total of 314 pediatric residents, representing $111 \%$ (which exceed the required representative sample of 282 participants) of the calculated representative sample, completed and returned the questionnaire for analysis (with a response rate of $30 \%$ ). Approximately $53.6 \%$ of the participants were female. Participating residents were from all regions of Saudi Arabia. Most of them were from the central region of Saudi Arabia (Table 1). Respondents were skewed towards the younger age group (25-30 years). Responses were received from residents in all clinical years with the majority in the fourth year of residency.

When asked on their preferences regarding the 24-hour on-call shift, 286 (91.1\%) of the residents preferred not to continue with this system. Residents ranked several indicators that they perceived as a negative impact due to the 24-hour on-call system. The first ranked indicator was missing academic activities and elective rotations post-call (mean 3.1 [SD 1.3], RII $90.9 \%$ ), and the second was decreased performance and decision-making skills during night duty (mean 3.5 [SD 1.0], RII 88.1\%). These indicators were followed by the residents' overall well-being and health, patients' exposure to potentially adverse events, the continuity of the patients' care post-call and the effect on residents' memory during night duty (Table 2 ). The overall mean perceived negative effect of the 24-hour on-call system on the 6 indicators was 3.5 out of 4 points $(S D=0.6)$. The one-way ANOVA test showed that residents with various residency training level perceived significantly different more negative impact from the 24-hours-

Table 1 - Baseline characteristics of the respondents' and its relationship with the overall perception of the impact of the 24-hour on-call system $(\mathrm{N}=314)$.

\begin{tabular}{lrlcl}
\hline Variables & n $(\%)$ & Mean (SD) & Statistic & P-value \\
\hline Age (years) & & & & \\
$\leq 30$ & $258(82.2)$ & $3.4(0.6)$ & $\mathrm{t}(312)=1.270$ & 0.207 \\
$>30$ & $56(17.8)$ & $3.5(0.5)$ & & \\
Gender & & & & \\
$\quad$ Male & $146(46.5)$ & $3.4(0.6)$ & $\mathrm{t}(312)=0.346$ & 0.729 \\
$\quad$ Female & $168(53.6)$ & $3.5(0.6)$ & & \\
Residency training level & & & & \\
R-1 & $72(22.9)$ & $3.2(0.7)$ & $\mathrm{f}(4,309)=4.780$ & 0.001 \\
R-2 & $46(14.6)$ & $3.6(0.6)$ & & \\
R-3 & $70(22.3)$ & $3.6(0.5)$ & & \\
R-4 & $80(25.5)$ & $3.5(0.5)$ & & \\
Graduated R-5 & $46(14.6)$ & $3.5(0.5)$ & & \\
Saudi Region & & & & \\
Eastern and North & $46(14.6)$ & $3.4(0.6)$ & $\mathrm{f}(2,311)=1.010$ & 0.365 \\
Western and & $115(36.3)$ & $3.5(0.6)$ & & \\
Southern & & & & \\
Central & $153(48.7)$ & $3.4(0.6)$ & & \\
\hline
\end{tabular}

Table 2 - Residents' perceived negative impact of the 24-hour on-call shift on their medical performance and well-being.

\begin{tabular}{|c|c|c|c|}
\hline Indicators & $\begin{array}{c}\text { Mean } \\
(\mathrm{SD})\end{array}$ & RII\% & Rank \\
\hline $\begin{array}{l}\text { Resident's overall well-being and } \\
\text { health }\end{array}$ & $3.4(1.2)$ & 87.5 & 3 \\
\hline $\begin{array}{l}\text { Decreased performance and } \\
\text { decision-making during night } \\
\text { duty due to fatigue }\end{array}$ & $3.5(1.0)$ & 88.1 & 2 \\
\hline $\begin{array}{l}\text { Effect on memory during night } \\
\text { duty }\end{array}$ & $2.7(1.5)$ & 67.7 & 6 \\
\hline $\begin{array}{l}\text { Missing academic activities in } \\
\text { the sub-specialty and elective } \\
\text { rotations after their } 24 \text {-hour shift }\end{array}$ & $3.1(1.3)$ & 90.9 & 1 \\
\hline $\begin{array}{l}\text { Continuity of patient care post- } \\
\text { call (daytime) }\end{array}$ & $3.0(1.7)$ & 69.7 & 5 \\
\hline $\begin{array}{l}\text { Exposing patients to potential } \\
\text { adverse events due to fatigue }\end{array}$ & $3.4(1.4)$ & 81.7 & 4 \\
\hline
\end{tabular}


oncall system as their training level gets higher ( $p=0.001$ ) (Table 1). The post-hoc testing found that residents level-1 perceived significantly lower negative impact from the 24-hours on-call system (mean=3.21, $\mathrm{SD}=0.69)$ than the level-2 residents (mean $=3.57$, $\mathrm{SD}=0.61$ ), $p=0.007$, the level 3 residents (mean $=3.56$, $\mathrm{SD}=0.54), p=0.002$, as well as significantly lower the level-4 residents (mean $=3.48, \mathrm{SD}=0.47) p=0.011$.

Discussion. In November 2014, the SCFHS formed the National Steering Committee on Residents' Duty Hours to reach a national consensus regarding the duty hours; it recommended a maximum of 24 hours of in-hospital duty hours. ${ }^{15}$ This period can be extended by up to 6 hours to ensure a safe transition of patient care and continuity of care, the completion of paper work, and the attending of academic activities. However, a new patient should not be assigned to residents after completion of their 24-hour shift. ${ }^{15}$

We conducted this study to assess pediatric residents' perceptions of the impact of the 24-hour shift on their well-being and education as well as its effect on patient safety and to put into evidence the need to move toward a more restricted working hour system. Our analysis showed that residents perceived the 24-hour on-call system to have a substantial negative impact at multiple levels, including missing academic activities, which was ranked first among the other indicators. This indicator was followed by the negative impact on residents' performance during night duty due to fatigue, residents' overall well-being, patient care and patient exposure to potentially adverse events, and interruption of continuity of care. Lastly, impaired working memory capacity was highlighted by the residents.

Our results are consistent with those of multiple international reports linking long working hours to a variety of negative outcomes, including resident performance and patient safety. ${ }^{3,20-23}$ These consistent reports compelled many international jurisdictions to restrict the duty hours for residents. ${ }^{3,24}$ In Quebec, for example, residents' shift hours have been limited to a maximum of 16 hours. ${ }^{25}$ In June 2013, the steering committee of the Royal College of Physicians and Surgeons of Canada reached a consensus that training centers should avoid duty periods of 24 or more consecutive hours without restorative sleep and recommended the development of a plan for fatigue risk management for residents. ${ }^{26}$ Some researchers reported that adherence to work hour limitations did not prevent residents from experiencing excessive daytime sleepiness post-on-call shifts. ${ }^{27}$ However, other investigators reported that decreasing in-training working hours improved alertness and was associated with a reduction in medical errors. ${ }^{3,24}$ While some researchers found that residents reported an improvement in their overall well-being due to the implementation of work hour limitations, they also reported that such work hour limitations negatively impacted patient care and resident education. ${ }^{28,29}$ One of the suggested solutions to overcome these issues is transitioning to the night float system. Although different models exist, the night float system was implemented in different institutions in Canada with the aim of restricting resident duty hours and complying with the duty hour restrictions policy. ${ }^{25,30}$ Several surveys conducted on residents across various disciplines reported an overall positive perception of restricting residents' working hours. ${ }^{3,20,22,31,32}$ One survey conducted on pediatric residents in a tertiary care pediatric and perinatal hospital in Tokyo, Japan showed an overall agreement by residents to rescind the 24-hour duty shift and transition to the night float system. ${ }^{31}$ In another survey that investigated the implications of transitioning to a resident night float system, researchers found that patient outcomes (including mortality rates and length of hospital stay) were not impacted by the implementation of the night float system. ${ }^{32}$ Additionally, residents perceived the night float system to be positive for patient care and resident education.

Study limitations. This study include its crosssectional design and self-reporting by the residents whose recall may be selective. Another major limitation of this study is that we documented residents' subjective perceptions of the 24-hour on-call system rather than objective measurements, such as the rate of adverse events in patients or resident performance on validated learning assessments. While this study was not designed to investigate the effect of restricting in-hospital working hours for trainees, the current findings suggest that it might be beneficial to restrict residents' working hours. Therefore, we suggest starting the night float system in different institutions as a quality improvement pilot project and to identify its applicability in the different pediatric training centers in Saudi Arabia.

In conclusion, we found that the 24-hour on-call system negatively impacts residents' well-being and education and patient safety. Pediatric residency training programs in Saudi Arabia should consider resident duty hour reform and evaluate new on-call models to improve resident well-being and training and improve patient care. Given that this area of research has shown variable results regarding the effects of resident duty hour reform on patient care, future studies should objectively investigate the implications of restricting in-hospital hours on residents' clinical performance and learning, patient outcomes, and patient care continuity. 
Acknowledgment. The author thank the residents who participated in this survey and the staff of the academic department at the Saudi Commission for Health Specialties for facilitating the delivery of the survey to the pediatric residents across Saudi Arabia. Lastly, the author gratefully acknowledge College of Medicine Research Center, Deanship of Scientific Research, King Saud University, Riyadh, Saudi Arabia.

\section{References}

1. Auger KA, Landrigan CP, Gonzalez del Rey JA, Sieplinga KR, Sucharew HJ, Simmons JM. Better rested, but more stressed? Evidence of the effects of resident work hour restrictions. Acad Pediatr 2012; 12: 335-343.

2. Starmer AJ, Sectish TC, Simon DW, Keohane C, McSweeney ME, Chung EY, et al. Rates of medical errors and preventable adverse events among hospitalized children following implementation of a resident handoff bundle. JAMA 2013; 310: 2262-2270.

3. Bolster L, Rourke L. The Effect of Restricting Residents' Duty Hours on Patient Safety, Resident Well-Being, and Resident Education: An Updated Systematic Review. J Grad Med Educ 2015; 7: 349-363.

4. Baer TE, Feraco AM, Tuysuzoglu Sagalowsky S, Williams D, Litman HJ, Vinci RJ. Pediatric Resident Burnout and Attitudes Toward Patients. Pediatrics 2017; 139: (3).

5. Sterling L, McCaffrey C, Secter M, Rich R, Green J, Shirreff L, et al. Development of a Night Float Call Model for Obstetrics and Gynaecology Residency: The Process and Residents' Perceptions. J Obstet Gynaecol Can 2016; 38: 1061.e.1-1064.e1.

6. Mathew R, Gundy S, Ulic D, Haider S, Wasi P. A Reduced Duty Hours Model for Senior Internal Medicine Residents: A Qualitative Analysis of Residents' Experiences and Perceptions. Acad Med 2016; 91: 1284-1192.

7. Patel MS, Volpp KG, Small DS, Hill AS, Even-Shoshan O, Rosenbaum L, et al. Association of the 2011 ACGME resident duty hour reforms with mortality and readmissions among hospitalized Medicare patients. JAMA 2014; 312: 2364-2373.

8. Temple J. Resident duty hours around the globe: where are we now? BMC Med Educ 2014; 14: S8.

9. Moonesinghe SR, Lowery J, Shahi N, Millen A, Beard JD. Impact of reduction in working hours for doctors in training on postgraduate medical education and patients' outcomes: systematic review. BMJ 2011; 342: d1580.

10. Fletcher KE, Underwood W, Davis SQ, Mangrulkar RS, McMahon LF, Saint S. Effects of work hour reduction on residents' lives: a systematic review. JAMA 2005; 294: 1088-100.

11. Shanafelt TD, Boone S, Tan L, Dyrbye LN, Sotile W, Satele D, et al. Burnout and satisfaction with work-life balance among US physicians relative to the general US population. Arch Intern Med 2012; 172: 1377-1385.

12. Al-Nozha MM. Postgraduate medical education in Saudi Arabia: the present and the coming decade. Ann Saudi Med 1985; 5: 197-198.

13. Herdson PB. The Organization of Postgraduate Medical Training in the Kingdom of Saudi Arabia. Ann Saudi Med 1987; 7: 1-2.

14. Shuaib T. Validity of In-Training Evaluation Report (ITER) in Saudi Pediatric Residency Training. Single center experience. [Updated 2018 May 1; Accessed 2018 Jan 22]. Available from: https://www.mededpublish.org/manuscripts/1390/v1.aspx
15. Saudi Commission for Health Specialties. Saudi Board Pediatric Curriculum. Saudi Commission for Health Specialties; 2014 [cited 2019 Jun 27]. Available from: https://www.scfhs.org.sa/ examinations/TrainingExams/DocLib/Pediatric\%20new.pdf

16. AlSohime F. Research involvement and obstacles among trainees enrolled in a pediatric residency program in Saudi Arabia. Int J Pediatr Adolesc Med 2018; 5: 88-91.

17. AlSohime F, NurHussen A, Temsah M-H, Alabdulhafez M, Al-Eyadhy A, Hasan GM, et al. Factors that influence the self-reported confidence of pediatric residents as team leaders during cardiopulmonary resuscitation: A national survey. Int J Pediatr Adolesc Med 2018; 5: 116-121.

18. Fabreau G, Elliott M, Khanna S, Minty E, Wallace JE, de Grood J, et al. Shifting perceptions: a pre-post study to assess the impact of a senior resident rotation bundle. BMC Med Educ 2013; 13: 115.

19. Holt GD. Asking questions, analysing answers: relative importance revisited. Constr Innov 2014; 14: 2-16.

20. Gordon MB, Sectish TC, Elliott MN, Klein D, Landrigan CP, Bogart LM, et al. Pediatric residents' perspectives on reducing work hours and lengthening residency: a national survey. Pediatrics 2012; 130: 99-107.

21. Ernst F, Rauchenzauner M, Zoller H, Griesmacher A, Hammerer-Lercher A, Carpenter R, et al. Effects of 24 h working on-call on psychoneuroendocrine and oculomotor function: a randomized cross-over trial. Psychoneuroendocrinology 2014; 47: 221-231.

22. Moeller A, Webber J, Epstein I. Resident duty hour modification affects perceptions in medical education, general wellness, and ability to provide patient care. BMC Med Educ 2016; 16: 175.

23. Mahan JD. Burnout in Pediatric Residents and Physicians: A Call to Action. Pediatrics 2017; 139: (3).

24. Auger KA, Jerardi KE, Sucharew HJ, Yau C, Unaka N, Simmons JM. Effects of the 2011 Duty Hour Restrictions on Resident Education and Learning From Patient Admissions. Hosp Pediatr 2014; 4: 222-227.

25. Pattani R, Wu PE, Dhalla IA. Resident duty hours in Canada: past, present and future. CMAJ 2014; 186: 761-765.

26. National Steering Committee on Resident Duty Hours. Fatigue, risk and excellence: towards a pan-Canadian consensus on resident duty hours. Ottawa $(\mathrm{ON})$ : The Royal College of Physicians and Surgeons of Canada; 2013.

27. Reddy R, Guntupalli K, Alapat P, Surani S, Casturi L, Subramanian S. Sleepiness in medical ICU residents. Chest 2009; 135: 81-85.

28. Bismilla Z, Breakey VR, Swales J, Kulik DM, Pai N, Singh N, et al. Prospective evaluation of residents on call: before and after duty-hour reduction. Pediatrics 2011; 127: 1080-1087.

29. Stroud L, Oulanova O, Szecket N, Ginsburg S. "The benefits make up for whatever is lost": altruism and accountability in a new call system. Acad Med J Assoc Am Med Coll 2012; 87: 1421-1427.

30. Drolet BC, Christopher DA, Fischer SA. Residents' response to duty-hour regulations--a follow-up national survey. $N$ Engl J Med 2012; 366: e35.

31. Nomura O, Mishina H, Kobayashi Y, Ishiguro A, Sakai H, Kato H. Limitation of duty hour regulations for pediatric resident wellness. Medicine (Baltimore) 2016; 95: (37).

32. Davis MC,- Kuhn EN, Agee BS, Oster RA, Markert JM. Implications of transitioning to a resident night float system in neurosurgery: mortality, length of stay, and resident experience. J Neurosurg 2016; 126: 1269-1277. 